\title{
Building an Implementation Model of IoT and Big Data and Its Improvement
}

\author{
Jonny $^{1 *}$, Kriswanto ${ }^{2}$, Matsumura Toshio ${ }^{3}$ \\ ${ }^{1}$ Department of Industrial Engineering, Faculty of Engineering, Bina Nusantara University, Jl. KH Syahdan \\ No. 9, Palmerah, Jakarta 11410, Indonesia \\ ${ }^{2}$ Department of Accounting, Faculty of Economics and Communication, Bina Nusantara University, Jl. KH \\ Syahdan No. 9, Palmerah, Jakarta 11410, Indonesia \\ ${ }^{3}$ Graduate School of Language and Culture, Studies in Language and Society, Osaka University, 8-1-1, \\ Aomatani, Minoh City, Osaka, Japan
}

\begin{abstract}
Emerging technologies had marked the emergence of the Industry 4.0 era. Despite the problems experienced with COVID-19, many experts believe that Industry 4.0 is an inevitable reality that many businesses must face in the future. One of those technologies is the Internet of Things (IoT), which may generate so-called "big data" that will be useful for business insight. However, after performing a rigorous literature review, articles related to the impact of the IoT and big data implementations for business performance in the form of a model were rarely found. Among the available literature, some elements that may be considered are: (1) business process improvement; (2) marketing strategies; (3) business management innovation; and (4) business performance. Therefore, this paper proposes an implementation model of IoT and big data to pursue business performance. Thus, a survey was conducted with managerial respondents from the manufacturing industry. For analysis purposes, a partial least squares structural equation modeling (PLS-SEM) methodology was implemented to examine the fitness of the model. The analysis was conducted in Smart PLS 3.0, and the goodness of fit (GoF) calculated for this model was 0.63 , larger than the required 0.38 for a robust and accurate result. This model was implemented in a sample manufacturing company to seek improvement. Regarding this effort, several improvements were added as input by the manufacturing players to enhance the model.
\end{abstract}

Keywords: Big Data; IoT; Smart PLS 3.0

\section{Introduction}

Long before the COVID-19 pandemic spread around the world, business faced the advent of emerging technologies that marked the start of the Industry 4.0 era. The adoption of these technologies for business purposes has been accelerating since the pandemic. This includes the adoption of the Internet of Things (IoT), which is enabled by the advancement of internet technology and other devices. By adopting this platform, multiple devices, such as sensors, cameras, and other communication/computing hardware, can be interconnected. The IoT capability enables them to communicate with each other to run any instructions given to them in providing desired functionality. In general, there are three categories of applications that have been proposed for the use of IoT platforms: lifestyle improvement for an individual, business process improvement for a business, and city 
improvement for government as a form of Society 5.0 development. For individuals, the improvement may be in the form of wearable devices and smart home appliances. This adoption can enhance the quality of life for those individuals who use those applications. For businesses, it can be in the form of healthcare systems or industrial automation that improves the business process of a company so that it may more effectively and efficiently serve its customers, resulting in an improved competitive advantage (Kudryavtseva and Skhvediani, 2020). For governments, this adoption can be in the form of smart cities, which may also accelerate Society 5.0 development (Acar and Acar, 2012; Agrawal et al., 2018). These possibilities have encouraged many entities to apply this technology to enhance the quality of lives of the individuals they serve. Thus, it is understandable that IoT applications have grown rapidly to reach about 43 billion units in 2023 (Ahmed et al., 2017). The main reason for those entities in adopting this technology is due to its ability in computing and communicating so that real-time information can be solicited as support for management to make better decisions regarding their activities.

At the business level, many companies that have adopted the IoT have gained a competitive advantage in the form of improved products and services. This has allowed them to obtain more business opportunities in the digital era. This is because the IoT possesses many advantages in learning customer behaviors, attitudes, and choices, which are useful for marketing studies. First, digitalization can be supported by using the IoT so that processing and routine activities can be enhanced (Akhlaghi and Asadi, 2002). Second, the use of the internet and information sharing can also be enhanced with the IoT so that a company can improve its relationship with its customers (Boyes et al., 2018; Bijmolt et al., 2021). The use of an IoT platform can generate a large volume of information, which is one form of what has become popularly known as "big data" (Berawi, 2018). Most of the data are in an unstructured form because they are from a variety of sources and are of different types, such as images, video, and audio. These unstructured data will not mean anything unless they can be carefully structured and analyzed using big data analytics; companies can then use the information to gain insight for better decision-making (Chui et al., 2010; De Mauro et al., 2015). This is especially important because this platform's devices and services are varied and may include smartphones, online transactions, social networks, electronics, and machining communications (Economist, 2010). Customer behavior that is captured through a collection of sensors of an IoT platform is often highlighted in descriptions of possible systems. However, from a case study of a typical industrial application, it was reported that the utilization of data from about 30,000 sensors was only about $1 \%$ of the data. This may change as systems become more integrated.

While there are many advantages in harnessing the use of IoT and big data, previous studies have shown that this field of research is still in the early stages of knowledge development. Some of them discuss the concept of IoT without further discussion on how it may impact business performance. Thus, within the focus on the adoption and utilization of this platform, a gap of knowledge still exists. This gap is especially interesting for study because of its relation to big data utilization for better business performance. In order to address this gap of knowledge in the field, this paper proposes a model as guidance for harnessing IoT and big data for better business performance, especially with regard to the manufacturing industry. The research objectives were: (1) develop a model for implementing IoT and big data; (2) investigate what elements should be considered when ensuring the benefits of IoT and big data adoption for better business performance; and (3) form guidance for businesses that are interested in implementing IoT and big data for gaining a competitive advantage. 


\section{Literature Review}

\subsection{Internet of Things (IoT)}

The phrase "Internet of Things" consists of two words: (1) "internet" referring to network technology; and (2) "things" meaning objects that can become connected to one another through that technology. In this platform, both physical and virtual objects can be connected and function as they are instructed. The IoT enables communication automatically among devices and provides services that can benefit individuals. By using this platform, both a company and its customers can gain many advantages by supporting the customer in making good choices regarding products and services used (De Mauro et al., 2015). In the industrial field, the IoT has grown as the industrial IoT for better regulating and monitoring industrial systems (Del Giudice, 2016; De Mauro et al., 2018). Through this technology, many events and changes in structural form can be better monitored so that security and risk matters may be better handled, resulting in cost and time savings, improved quality, and productivity improvement (Donalek et al., 2014).

\subsection{IoT and Big Data}

The use of IoT may generate a great deal of data and information, which is so large in terms of its volume, velocity, variety, veracity, and validity that it needs to be examined using big data analytics (Dubey et al., 2021). Volume means the flow of a large amount of data. Velocity indicates the speed of the data generation in a real-time manner through a continuous connection (Dwivedi et al., 2019). Variety means different data sources from the IoT (Ebner et al., 2014). In addition, there are characteristics (1) related to the reliability and data quality (Erevelles et al., 2016); (2) related to the value, which is determined by the availability of insight from data analysis (Gandomi and Haider, 2015; Erevelles et al., 2016); (3) related to variability in the context of the source of the data production (Guo et al., 2013). The ubiquitous data generated from an IoT extend it to big data (Gupta et al., 2017). Big data analytics that result from the IoT represent big opportunities for a business to develop a market based on new customer insights and therefore may improve their strategic planning and implementation (Gupta et al., 2019). Big data and the IoT have been recognized as part of a disruption revolution regarding their potency to provide better insight in order to gain a competitive advantage for a company in the industry (GutierrezGutierrez et al., 2018; Gutierrez et al., 2019). For these reasons, companies are encouraged to equip themselves with a competitive infrastructure for better data generation by the IoT.

\subsection{Business Digital Transformation}

Managerial function and marketing strategy have been reshaped by the use of IoT and big data as a digitalization initiative in many companies (Cullen et al., 2014). It represents a new way to manage both business and marketing for companies in the era of the Industry 4.0 revolution. Daily human activities and relationships have been radically changed by this new paradigm, including the way to manage and process the business in a company. For business survival and gaining competitive advantages, a business digital transformation like this is essentially needed. Not only that, but management, organization, and production processes should also be sufficiently transformed through reengineering (Davenport, 2014). For that purpose, core business processes should be redesigned starting with information technology (IT) processes to others in order to improve organizational performance through digitalization (Donalek et al., 2014). This is based on the cooperation between business process digitalization and IT in creating communication skills, a group orientation, coordination, and real-time capabilities (Ebner et al., 2014). Through this, companies' production processes, new products, and services are supported by the IoT and digitalization initiatives with efficient and modern technologies. Along with that, data 
capture can generate big data related to behavior prediction, choice decisions, and consumption rates as input for decision-making processes and strategy planning. This can be done because IoT adoption transforms business process focuses from physical products to data-driven services (Gutierrez-Gutierrez et al., 2018).

\subsection{IoT and Big Data for Business Performance}

From an industrial application perspective, various connected devices can be enabled to contribute as part of an IoT platform. IoT enables production strategy and communication among various instruments and machinery (Acar and Acar, 2012). In its development, an intelligent machinery system can be connected for real-time big data generation in various manufacturing processes. In a healthcare environment, a hospital's core business processes are totally reshaped based on the contribution of IoT adoption. In this situation, telemedicine can be used to improve its services. In addition, medical decisions and human health monitoring can also be advanced by using telemedicine and health data management (Akhlaghi and Asadi, 2002). In the service industry, optimal intelligent technology and traffic and safety management can be enhanced by an IoT platform. In conclusion, a digital transformation that improves business processes can be achieved by an IoT and big data transformation (Cullen et al., 2014).

The impact of a digital transformation through the adoption of IoT and big data on business performance has been reviewed by previous articles that have covered several elements (Sestino et al., 2020). The first is business process improvement. Managers and researchers can transform business processes using smart IoT devices so that they can ensure automation initiatives for sustainable value and self-optimalization (Ahmed et al., 2017). The second is business management innovation. The spread of intelligent space is ensured using an IoT mix. In this context, people and the technology system interaction can be enabled in a physical and digital environment (Chui et al., 2010). The third is marketing strategies. Gaps or emerging trends in consumer behavior can be immersed using consumption data that are generated from the IoT and big data adoption (Sestino et al., 2020).

\section{Methodology}

\subsection{Data Collection}

A model of IoT and big data implementation was constructed through quantitative research. For model development purposes, a questionnaire survey for managers in the manufacturing industry in Indonesia was conducted. In the model, four elements were to be examined: (1) business process improvement; (2) marketing strategies; (3) business management innovation; and (4) business performance. A Likert scale ranging from strongly disagree (1) to strongly agree (5) was used to record responses from the participants. Experts were involved in providing recommendations on the model and questionnaire through a pilot study. From this, the conceptual framework of the IoT and big data implementation model was constructed, as shown in Figure 1. 


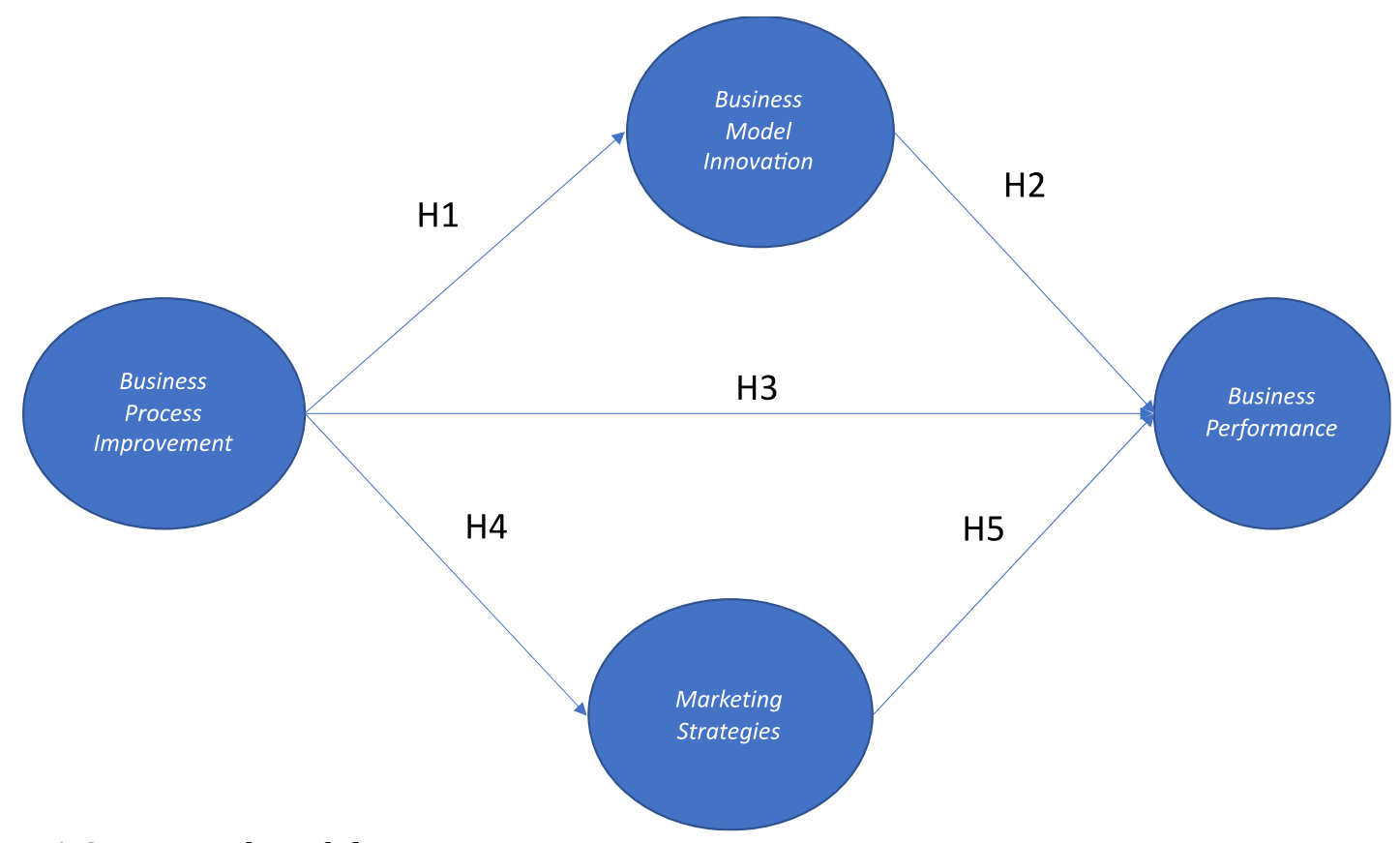

Figure 1 Conceptual model

The figure shows a model of the IoT and big data implementation to achieve better business performance, which consists of four elements. It shows that business performance can be achieved whether by business model innovation, business process improvement, or marketing strategies, while either business model innovation or marketing strategies are impacted by business process improvement through the implementation of IoT and big data. From the figure, there are five hypotheses to be tested in this paper.

\subsection{Sampling}

Potential respondents were managers in companies in various industries; they were contacted at different locations in Indonesia due to a large study population. Because the maximum number of paths was three (as shown in Figure 1), then a minimum sample size was about 30 as result of multiplying three by 10 (De Mauro et al., 2018). However, due to the enthusiasm of the respondents, the collected sample was larger, with 142 responses. Out of this number, 22 responses were determined to be invalid to do the absence of the use of IoT and big data in the respondents' companies. Thus, there were 120 valid responses from the manufacturing industry to be evaluated using partial least squares structural equation modeling (PLS-SEM; Ardi et al., 2020) with the SmartPLS 3.0 software.

\subsection{Data Analysis}

Questionnaires containing 18 questions were carefully designed and tested before being distributed to managers in the manufacturing industry as part of this research. For business process improvement, there were five questions: (1) IoT use for process automation; (2) IoT use for production process; (3) data scientist recruitment for big data analytics; (4) manager uses of big data for strategy planning; and (5) manager uses of big data for production process transformation. For business model innovation, there were two questions: (1) manager uses big data for trend and scenario planning; and (2) company uses IoT and big data for re-engineering the business model. For marketing strategies, there were six questions: (1) niche market identification; (2) real-time data-based campaign and decision-making; (3) customer experience improvement; (4) touchpoint improvement; (5) product improvement; and (6) data transaction collection for marketing strategy planning; For business performance, there were five questions: (1) inefficiency identification; (2) 
effective resource allocation; (3) security management improvement; (4) supply chain improvement; and (5) digital platform improvement.

Data from 120 respondents with valid responses were included for detailed analysis based on the conceptual model. To test the hypotheses and determine the fitness of the model, Smart PLS 3.0 was used. The model fitness metric used in this research was the goodness of fit index.

Smart PLS 3.0 was used to process all the responses from the managers using the conceptual model shown in Figure 1 as a path diagram. From the results, the goodness of fit index was calculated to test whether the model was accurate and robust with a threshold value of 0.38 (Tenenhaus et al., 2004). The hypotheses could then be tested using a $p$-value smaller than 0.05 to indicate that those relationships were statistically significant (Jonny and Kriswanto, 2021).

\section{Results and Discussion}

The data collected from the respondents was input into Smart PLS 3.0, and the path diagram was also depicted using the program. After that, the goodness of fit was calculated as 0.63 (larger than the required threshold of 0.38). Therefore, it can be said to be a robust and accurate model for this dataset with the specific loadings described below. By having this value, the model can be said eligible to provide guidance for organizations in implementing IoT and big data for better business performance.

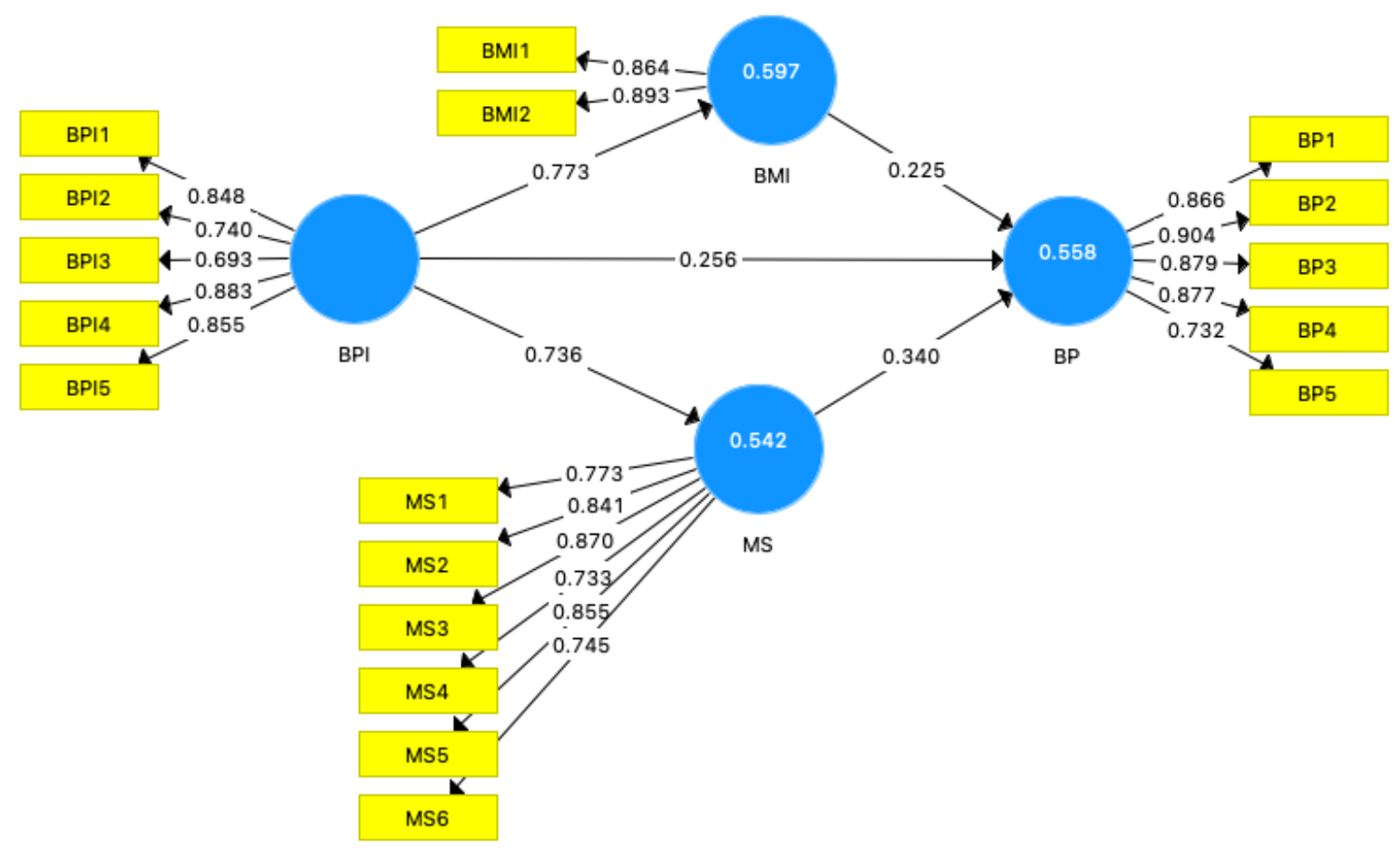

Figure 2 IoT and big data implementation model

Figure 2 shows the PLS-SEM results. Several findings can be drawn. First, business process improvement significantly influenced business model innovation (BMI), $r=0.773$, $p<0.001$. Second, business process improvement (BPI) significantly influenced marketing strategies, $\mathrm{r}=0.736, p<0.001$. These two were both strong loadings. Third, business model innovation (BMI) significantly influenced business performance (BP), $\mathrm{r}=0.225, p=0.042$. Fourth, business process improvement (BPI) significantly influenced business 
performance (BP), $r=0.256, p=0.044$. However, these last two relationships were both very weak. Fifth, marketing strategies (MS) did not significantly influence business performance, $p=0.068$.

\section{Case Study: Implementation of IoT and Big Data in a Typical Manufacturing Company}

The model shown in the previous section has been socialized and implemented in a typical manufacturing company. There are some suggestions regarding the implementation that resulted in priority numbering in which business process improvement was designated to the activity with highest priority to be done with the help of IoT and big data. Additionally, IoT and big data adoption in the marketing strategy field has been strengthened to ensure its influence on business performance.

\section{Conclusions}

This paper has resulted in a preliminary model of IoT and big data implementation to enhance business performance. The model covers marketing strategies, business management innovation, business process improvement, and business performance. Among the five hypotheses, two hypotheses were statistically significant with strong relationships, two were significant but weak, and one was insignificant. With this dataset, business process improvement was shown to significantly impact business model innovation and marketing strategies. Thus, practice in a typical manufacturing company is strengthened to ensure its relationship. Although this model is still preliminary, it can still provide guidance for companies when they want to implement and ensure that adoption is beneficial for business performance. However, this research still has limitations in the form of the sample size, the respondents' profiles, and the need to explore the model further with additional data. Therefore, for future research, it is recommended that researchers take these matters into consideration.

\section{Acknowledgements}

This work is supported by the Research and Technology Transfer Office, Bina Nusantara University as a part of Bina Nusantara University's International Research Grant entitled "Developing Internet of Things (IoT) dan Big Data Implementation Model" with contract number: 017/VR.RTT/III/2021 and contract date: March 22, 2021.

\section{References}

Acar, A.Z., Acar, P., 2012. The Effects of Organizational Culture and Innovativeness on Business Performance in Healthcare Industry. Procedia - Social and Behavioral Sciences, Volume 58, pp. 683-692

Agrawal, A., Schaefer, S., Funke, T., 2018. Incorporating Industry 4.0 in Corporate Strategy. In: Analyzing the Impacts of Industry 4.0 in Modern Business Environments, BrunetThornton, R., Martinez, F. (eds.), IGI Global, Hershey, Pennsylvania, USA, pp. 161-176

Ahmed, E., Yaqoob, I., Hashem, I.A.T., Khan, I., Ahmed, A.I.A., Imran, M., Vasilakos, A.V., 2017. The Role of Big Data Analytics in Internet of Things. Computer Networks, Volume 129(Part 2), pp. 459-471

Akhlaghi, H., Asadi, H., 2002. Essentials of Telemedicine and Telecare. Wiley, Chichester, UK. Ardi, R., Iqbal, B.M., Sesarea, S., Komarudin, K., 2020. What Drives Individuals to Dispose of Waste Mobile Phones? A Case Study in Indonesia. International Journal of Technology, Volume 11(3), pp. 631-641 
Berawi, M.A., 2018. Utilizing Big Data in Industry 4.0: Managing Competitive Advantages and Business Ethics. International Journal of Technology, Volume 9(3), pp. 430-433

Bijmolt, T.H.A., Broekhuis, M., de Leeuw, S., Hirche, C., Rooderkerk, R.P., Sousa, R., Zhu, S.X., 2021. Challenges at the Marketing-Operations Interface in Omni-Channel Retail Environments. Journal of Business Research, Volume 122, pp. 864-874

Boyes, H., Hallaq, B., Cunningham, J., Watson, T., 2018. The Industrial Internet of Things (IIoT): An Analysis Framework Computers in Industry, Volume 101, pp. 1-12

Chui, M., Loffler, M., Roberts, R., 2010, The Internet of Things. McKinsey Quarterly Available Online at https://www.mckinsey.com/industries/technology-media-andtelecommunications/our-insights/the-internet-of-things

Cullen, K.L., Edwards, B.D., Casper, W.C., Gue, K.R., 2014. Employees' Adaptability and Perceptions of Change-Related Uncertainty: Implications for Perceived Organizational Support, Job Satisfaction, and Performance. Journal of Business and Psychology, Volume 29, pp. 269-280

Davenport, T.H., 2014. How Strategists Use "Big Data" to Support Internal Business Decisions, Discovery and Production. Strategy \& Leadership. Volume 42(4), pp. 45-50

De Mauro, A., Greco, M., Grimaldi, M., 2015. What is Big Data? A Consensual Definition and a Review of Key Research Topics. In: AIP Conference Proceedings, Volume 1644

De Mauro, A., Greco, M., Grimaldi, M., Ritala, P., 2018. Human resources for Big Data Professions: A Systematic Classification of Job Roles and Required Skill Sets. Information Processing \& Management, Volume 54(5), pp. 807-817

De Mauro, A., Greco, M., Grimaldi, M., 2019. Understanding Big Data Through a Systematic Literature Review: The ITMI Model. International Journal of Information Technology and Decision Making, Volume 18(04), pp. 1433-1461

Del Giudice, M., 2016. Discovering the Internet of Things (IoT) Within the Business Process Management: A Literature Review on Technological Revitalization. Business Process Management Journal, Volume 22(2), pp. 263-270

Donalek, C., Djorgovski, S.G., Cioc, A., Wang, A., Zhang, J., Lawler, E., Yeh, S., Mahabal, A., Graham, M., Drake, A., 2014. Immersive and Collaborative Data Visualization using Virtual Reality Platforms. In: Proceedings - IEEE International Conference on Big Data. IEEE Big Data, Washington, USA

Dubey, R., Gunasekaran, A., Childe, S.J., Fosso Wamba, S., Roubaud, D., Foropon, C., 2021. Empirical Investigation of Data Analytics Capability and Organizational Flexibility as Complements to Supply Chain Resilience. International Journal of Production Research, Volume 59(1), pp. 110-128

Dwivedi, Y.K., Hughes, L., Ismagilova, E., Aarts, G., Coombs, C., Crick, T., Duan, Y., Dwivedi, R., Edwards, J., Eirug, A., Galanos, V., Ilavarasan, P.V., Janssen, M., Jones, P., Kar, A.K., Kizgin, H., Kronemann, B., Lal, B., Lucini, B., Medaglia, R., Meunier-FitzHugh, K.L., Le MeunierFitzHugh, L.C., Misra, S., Mogaji, E., Sharma, S.K., Singh, J.B., Raghavan, V., Raman, R., Rana, N.P., Samothrakis, S., Spencer, J., Tamilmani, K., Tubadji, A., Walton, P., Williams, M.D., 2019. Artificial Intelligence (AI): Multidisciplinary Perspectives on Emerging Challenges, Opportunities, and Agenda for Research, Practice and Policy. International Journal of Information Management, Volume 57, https://doi.org/10.1016/j.ijinfomgt.2019.08.002

Ebner, K., Bühnen, T., Urbach, N., 2014. Think Big with Big Data: Identifying Suitable Big Data Strategies in Corporate Environments. In: Proceedings of the $47^{\text {th }}$ Annual Hawaii International Conference on System Sciences, Hilton Waikoloa, Big Island

Economist, 2010, Data, Everywhere: A Special Report on Managing Information. The Economist 
Erevelles, S., Fukawa, N., Swayne, L., 2016. Big Data Consumer Analytics and the Transformation of Marketing. Journal of Business Research, Volume 69(2), pp. 897-904 Gandomi, A., Haider, M., 2015. Beyond the Hype: Big Data Concepts, Methods, and Analytics. International Journal of Information Management, Volume 35(2), pp. 137-177

Guo, B., Zhang, D., Wang, Z., Yu, Z., Zhou, X., 2013. Opportunistic IoT: Exploring the Harmonious Interaction between Human and the Internet of Things. Journal of Network and Computer Applications, Volume 36(6), pp. 1531-1539

Gupta, A., Tsai, T., Rueb, D., Yamaji, M., Middleton, P., 2017. Forecast: Internet of Things Endpoints and Associated Services, Worldwide, 2017. Gartner. Available Online at https://www.gartner.com/en/documents/3840665/forecast-internet-of-thingsendpoints-and-associated-ser, Accessed on May 16, 2020

Gupta, R., Mejia, C., Kajikawa, Y., 2019. Business, Innovation and Digital Ecosystems Landscape Survey and Knowledge Cross Sharing. Technological Forecasting and Social Change, Volume 147, pp. 100-109

Gutierrez-Gutierrez, L.J., Barrales-Molina, V., Kaynak, H., 2018. The Role of Human Resource-Related Quality Management Practices in New Product Development: A Dynamic Capability Perspective. International Journal of Operations \& Production Management, Volume 38(1), pp. 43-66

Gutierrez, A., O'Leary, S., Rana, N.P., Dwivedi, Y.K., Calle, T., 2019. Using Privacy Calculus Theory to Explore Entrepreneurial Directions in Mobile Location-Based Advertising: Identifying Intrusiveness as the Critical Risk Factor. Computers in Human Behavior, Volume 95, pp. 295-306

Jonny., Kriswanto., 2021. Modelling the Use of Social Network Marketing in Indonesia. In: IOP Conference Series: Earth and Environmental Science

Kudryavtseva, T., Skhvediani, A., 2020. Effectiveness Assessment of Investments in Robotic Biological Plant Protection. International Journal of Technology. Volume 11(8), pp. 1589-1597

Sestino, A., Prete, M.I., Piper, L., Guido, G., 2020. Internet of Things and Big Data as Enablers for Business Digitalization Strategies. Technovation, Volume 98, doi: 10.1016/j.technovation.2020.102173

Tenenhaus, M., Amato, S., Vinzi, V.E., 2004. A Global Goodness-of-Fit Index for PLS Structural Equation Modeling. In: Proceedings of the XLII SIS Scientific Meeting, pp. 739-742 